\title{
Building Capacity to Cope with Climate Change-Induced Resource-Based Conflicts Among Grassroots Communities in Kenya
}

\author{
John Kibe Maguta, Daniel M. Nzengya, Chrocosiscus Mutisya, and \\ Joyce Wairimu
}

\section{Contents}

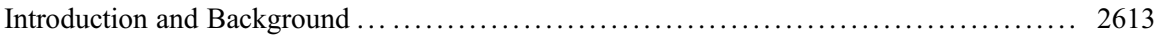

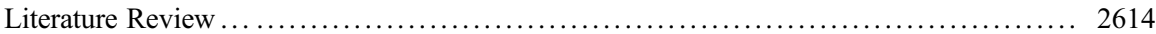

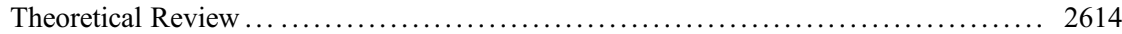

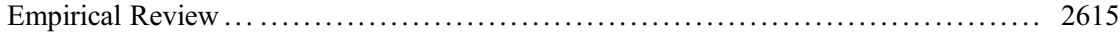

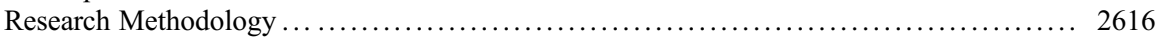

A Map of the Study Site ............................................... 2617

Brief Description of the Study Sites ..................................... 2618

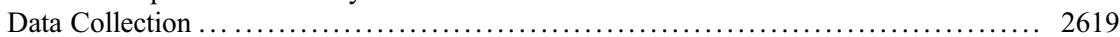

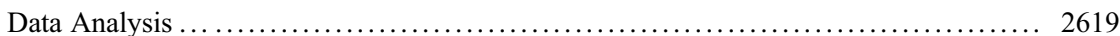

Results and Discussions ................................................... 2619

Sociodemographic Characteristics of the Sample ............................. 2619

Perceptions of Impacts on Climate Change on Livelihoods ..................... 2620

Citizens Perceptions of the Prevalence of Climate Change Induced Resource-Based

Conflicts ....................................................... 2622

Citizens' Perceptions of Contribution of Climate-Change to Resource-Based Conflicts ... 2625

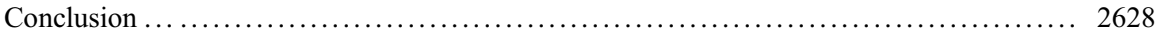

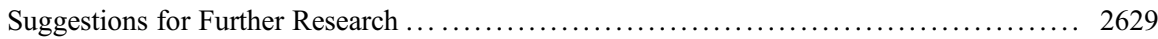

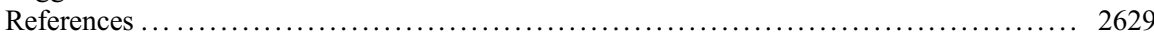

This chapter was previously published non-open access with exclusive rights reserved by the Publisher. It has been changed retrospectively to open access under a CC BY 4.0 license and the copyright holder is "The Author(s)". For further details, please see the license information at the end of the chapter.

J. K. Maguta ( $\square)$

Faculty of Social Science, St Paul's University, Limuru, Kenya

e-mail: kibemaguta@gmail.com

D. M. Nzengya $\cdot$ C. Mutisya $\cdot$ J. Wairimu

Department of Social Sciences, St Paul's University, Limuru, Kenya

e-mail: dnzengya@yahoo.com; chrocnjeru@gmail.com; Joycemathenge9@gmail.com 


\section{Abstract}

Kenya is among the world's most vulnerable countries to climate change-related stresses and extreme events. According to FAO, over $75 \%$ of the country is classified as arid and semiarid with rainfall availability and amounts quite unevenly spread across the different parts of the country. The country has very skewed distribution of water sources with the western area being relatively well endowed with abundant water resources. The exponential growth in the country's population over the years, together with rapid environmental degradation and poor water resource development programs, have worsened the country's vulnerability to the effects of climate change. Ethnic conflicts over land resources are common-place in Kenya's rural areas where majority of the people live and the effects of extreme climate change events are likely to exacerbate resource-based conflicts. In this chapter we explore the extent of climate change-induced resource conflicts in three counties along rainfall availability gradient, namely, Kiambu County which experiences relatively high rainfall and also high urban population, Machakos County, which generally experiences modest rainfall availability, and Makueni County regarded to be one of the most arid and semiarid counties in the country. Data were collected in 2017 using a closed ended questionnaire. Between-subjects MANOVA design was used to examine relationship between independent and dependent variables. Qualitative results of the open-ended question reveal that climate change impacts can be diverse, particularly for vulnerable regions such as arid and semiarid regions such as Makueni County. In this county, respondents mentioned nine ways climate change had impacted communities, with the most frequently mentioned impact being increasing food insecurity followed by increasing water shortages. Machakos followed with seven impacts mentioned starting with increased water shortages followed by scarcity of pasture. In Kiambu County, only four impacts were mentioned with food insecurity being frequently mentioned among the list of impacts of climate change in the county. Results of the descriptive and inferential statistics reveal that resource-based conflicts vary along the hydrological gradient. In Machakos County, resource-based conflicts are perceived to have risen during the last 5 years $(M=3.92, S D=0.66)$, followed by Makueni $(M=4.10, S D=0.670)$. Kiambu residents do not consider resource-based conflicts to have risen during the last 5 year, $(\mathrm{M}=2.50, \mathrm{SD}=1.38)$. Differences in severity of climate related conflicts are statistically significant, $F_{2,76}=12.78, p<0.01$. Also, climate change is strongly perceived to be a factor in the rise of resource-based conflicts in Machakos County $(\mathrm{M}=4.10, \mathrm{SD}=0.67)$. In Makueni County as well, climate change is perceived to be a significant contributor to resource-based conflicts $(\mathrm{M}=3.98, \mathrm{SD}=1.70)$. These findings have relevance on county and national policies targeted to build capacity to cope with climate change induced resourcebased conflicts among grassroot communities in Kenya.

\section{Keywords}

Climate change induced resource-based conflicts · Grassroot communities · Women $\cdot$ Adaptation projects $\cdot$ Kenya 


\section{Introduction and Background}

Global climate change is one of the major socioeconomic and environmental challenges facing communities in the twenty-first century. The impacts of climate variability including extreme climate events are many, complex, and wide-ranging, and include among other human conflicts. In the African continent, the impacts of global climate change are exacerbated by environmental degradation, political instability, poor governance and corruption, rapid population growth, and urbanization, largely in form of informal settlements. Impacts on the agricultural sector, especially impacts on export crops such as coffee are feared to affect the economic production and growth in different regions. Reduction in acreage under cash crops has meant low income. For the last few decades, climate change has affected many regions of the world. According to Hussein et al. (1999), climate change exacerbates conflicts. The authors have argued here that human activities coupled with droughts of the 1970s and 1980s caused a lot of tensions in Africa. Communities got into conflict with each other as they competed over diminishing resources. This view gets support from Benjaminsen and $\mathrm{Ba}$ (2009). According to the duo, the conflicts between farmers and herders in the Niger Delta of Mali were escalated by the droughts mentioned. Herders grazed into the grain fields of cultivators leading to conflicts that at times became violent. Such conflicts are thought to have undermined the loyalty to the government. Governments have been accused of favoring one party at the expense of the other. In the case of Mali, the government was accused of favoring farmers and it was not taken kindly by herders. This resulted to frequent conflicts leading to stagnation in development. Peters and Mayhew (2019) have mentioned the increasing conflicts in Africa and the Arabic states while Price (2019) has given details of worrying trends in Afghanistan all coming from climate change conflicts. It is evident that climate change has scared the world with the scare being more real as years pass by.

In sub-Saharan Africa, climate variability threatens to reverse the decades of government investments to eradicate extreme poverty. Africa faces some of the worst forms of conflicts, and it is feared that climate change will further confound governments' investments for peaceful coexistence amongst communities and nations. While majority of the sub-Saharan African nations failed to achieve the Millennium Development Goals, it is feared that climate variability potentially poses a significant threat to the region's efforts to achieve the Sustainable Development Goals (SDGs). Most countries in SSA rely on rain-fed agriculture for livelihoods and incomes, thus extreme events such as the increasing and more prevalent and prolonged droughts with the continent's limited surface water resources complicates achieving some of the SDGs such as ending poverty in all its forms, ending hunger and achieving food security as well as ensuring healthy lives and economic growth among others. Sub-Saharan Africa has incidentally the most rapidly growing urban population posing real threat to water available for food production and other economic activities. In the huge arid and semiarid areas of SSA that are predominantly the home of pastoral communities, growing scarcity of pasture and water for livestock is likely to remain a huge driver of conflicts. Limited investments on 
technology and weak institutions and governance further comprise sources of vulnerability to Africa's development sectors which include climate change.

Kenya is among the world's most vulnerable countries to climate change-related stresses and extreme events. Seventy-five percent of Kenya's land mass is classified as arid and semiarid with rainfall availability and amounts quite unevenly spread across the different parts of the country. The country's western region is relatively well endowed with abundant water resources. The exponential growth in the country's population over the years, together with rapid environmental degradation and poor water resource development programs, have worsened the country's vulnerability to the effects of climate change. Ethnic conflicts over land resources are common-place in Kenya's rural areas where majority of the people live and the effects of extreme climate change events are likely to exacerbate resource-based conflicts. In this chapter we explore the extent of climate change-induced resource conflicts in three counties along rainfall availability gradient, namely, Kiambu County which experiences relatively high rainfall and also high urban population, Machakos County, which generally experiences modest rainfall availability, and Makueni County regarded to be one of the most arid and semiarid counties in the country.

\section{Literature Review}

\section{Theoretical Review}

This chapter draws on Strain Theory which posits that achievements of individuals and communities is pegged on goals and aspirations in life, and whenever these goals and aspirations are threatened, conflicts are bound to take place. The extreme climatic changes taking place in the world are threatening the ability to achieve the desires of different individuals and the society at large leading to tensions and conflicts. According to Agnew (2012), inability to achieve different objectives and goals lead to change in behavior. When climate changes occur, the economic status of people gets affected negatively. Increasing desertification has led to diminishing fodder for animals as well as lower production on the part of cultivators. The conflicts witnessed between farmers and herders in Tanzania attest to this. According to Benjaminsen et al. (2009), the conflicts whose source was climatic changes left a lasting mark. Enmity and killings resulted. The approach taken by Strain Theory is Malthusian. As the amount and quality of resources decline, competition between individuals as well as groups increases. Meierding (2013) contends that competition over resources result to violent clashes. In the African region, competition over pasture and water has been the main source of conflicts. Increasing desertification has also contributed to these conflicts. As cited elsewhere in this work, the conflicts have resulted to dire consequences including the loss of lives. 
The Relative Deprivation Theory developed by Samuel Stouffer during World War II purports that people take action to acquire something that others possess and which they believe they too should have. According to Stouffer, opportunities, status, and desire for material gain at times lead to use of force. When resources become diminished or of lower quality, those who miss out feel disadvantaged in comparison to others. Those that are relatively deprived feel anger especially when they feel the privileged are not willing to share. Sunga (2014) contends that climate change creates conditions that make ethnic groups struggle for scarce resources. The author argues that those who fail to get the scarce resources are motivated to use violence which ends up in serious atrocities. The author views extreme climate change as a risk factor and a major cause of ethnic violence engulfing the developing countries. This argument raises serious concerns and calls for attention to the changing climate conditions across the world.

The Social Disorganization Theory has been used to explain the security implications of climate change. Due to climate change, communities have been on the move looking for less hostile weather to cultivate and herd animals. This has led to push and pull not only between man and man but also between man and wildlife. Communities become disorientated by climate change and this affects development. The energy and time that would have been devoted to economic progress is lost to look for better living conditions. Social cohesion and integration become compromised. Elsewhere in the African region, climate change has led to drought, landslides, desertification, pollution, sand storms, disease, hunger, and unusual weather (Folami and Folami 2013). In Northern Kenya, desertification has escalated with increase in sandstorms. Getting forage has become a hard task with conflicts over water increasing. The conflicts have at times led to deaths and fear. It is not uncommon for communities to attack their neighbors in the name of restocking when animals have been wiped out by drought.

\section{Empirical Review}

Climate change is arguably one of most serious environmental problems facing humans in the twenty-first century. The consequences of increasingly variable climate and extreme climate events are many and complex, among them resourcebased conflicts. Climate-related resource-based conflicts are extremely varied from local, regional, to global contexts. Climate variability may directly and indirectly trigger diverse conflicts. Conflicts may be triggered for instance when communities migrate as a response to cope with impacts to different areas where they exert increased competition for resources in their new destinations. The impacts of climate change are particularly more profound in communities where people rely on their immediate environment for basic needs. In Nigeria, for instance, Folami and Folami (2013) have noted that climate change has resulted into extreme droughts triggering severe water scarcity. 
Although impacts of extreme climate change events are felt most in the developing nations, developed nations too experience challenges of climate variability. In the United States, damages from tornadoes, floods, droughts, hurricanes, and wildfires during 2011 caused more than $\$ 200$ billion in losses and over 1,000 deaths. Tornadoes, floods, droughts, hurricanes, and wildfires were all attributed to climate change (Scott and Andrade 2012). In South Africa, it is feared that grain production is likely to reduce due to climate change. According to Kuhlmann et al. (2012), climate change has had disastrous effects on pollination of flowering plants. Bees have been noted to shift to the more suitable areas to survive. In the same line, climate change has lowered grain production leading to starvation for the people. The increase of starvation, hunger, and want is a trigger for conflicts.

The past 10 years have witnessed conflict with nature resulting from improved technology and the fact that man is demanding more from nature. In developing countries, conflicts with wildlife have increased. Elsewhere, improved technology has enabled the powerful to clear large areas of land and exploit the natural resources at an alarming rate. Since climate change does not limit itself to a geographic region, the effects of change are felt far and wide. In sub-Saharan Africa, many communities live in economically poor and marginal regions. They therefore experience shortage of water and pasture the greater part of the year. Arable land is scarce (Serdeczny et al. 2017; Hadush 2018).

In Northern Kenya and upper Eastern region of the country, most people depend on those scarce resources for survival. Since rainfall determines the availability of water, pasture, milk, crop yields, and so on, its failure causes a lot of stress. Resources that people depend on get scarcer. Drying of shallow wells and earth dams lead to pressure that more often than not culminates into full blown fighting. Witsenburg and Adano (2009) have noted that in Marsabit region, conflicts over water and pastures have become a common phenomenon particularly during dry spells. Also, the authors have noted a rising competition between livestock and wildlife over pasture and water.

\section{Research Methodology}

The study used a cross-sectional survey design to collect and analyze data. Survey method has several benefits; it allows rapid collection, analysis, and reporting of research findings over relatively short period of time. Longitudinal design may, however, be needed to allow observations of conflict related to resources use over time and the mechanism driving the conflicts. 


\section{A Map of the Study Site}

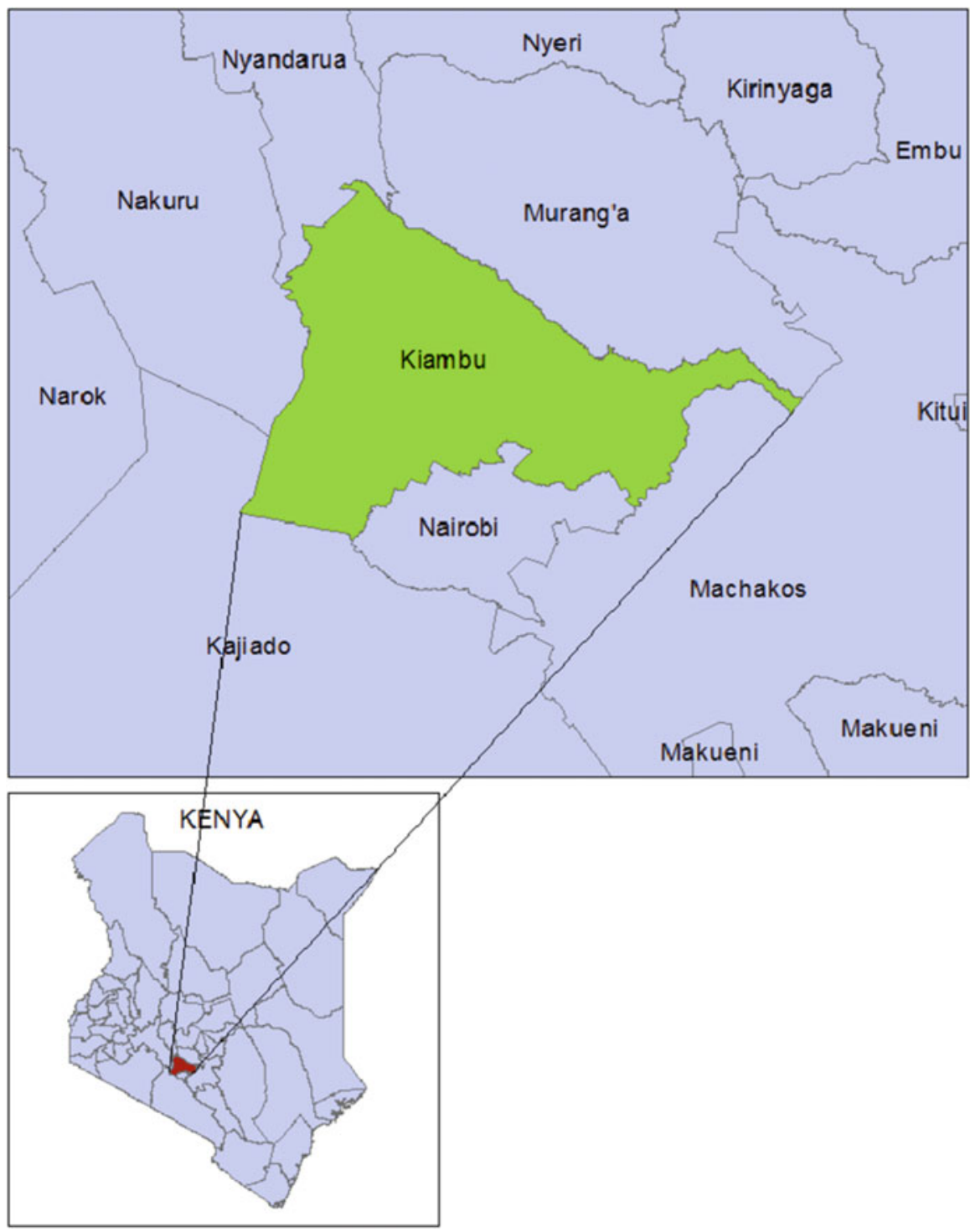




\section{Brief Description of the Study Sites}

\section{Kiambu County}

Kiambu County has warm weather with the warmest month being $18.7^{\circ} \mathrm{C}$ and the coolest month registering $12{ }^{\circ} \mathrm{C}$. The hottest months are January-March and September-October, while the coolest months are June and July. The rainfall aggregate for the county is $1000 \mathrm{~mm}$ annually. This is quite conducive for agriculture activities. Kiambu covers an area of 2,543.2 $\mathrm{km}^{2}$. It has a population of 2,417,735 people according to Kenya National Bureau of Statistics (GoK 2019). The population density is 658.14 people per $\mathrm{km}^{2}$. The population is predominantly Kikuyu community who comprise the most populous tribe in Kenya. Other ethnicities include Asian and Caucasian population working as businessmen or for various foreign missions. The county is cosmopolitan and hosts other communities such as Luhya, Luo, Maasai, Kamba, Meru, and Kalenjins, among others. The poverty index for the County is 21.3. The County relies mainly on agriculture and industries to sustain its economy.

\section{Machakos County}

Machakos County stretches from latitudes $0^{\circ} 45^{\prime}$ south to $1^{\circ} 31^{\prime}$ South and longitudes $36^{\circ} 45^{\prime}$ east to $37^{\circ} 45^{\prime}$ east. It is mainly semiarid with temperatures between $18{ }^{\circ} \mathrm{C}$ and $29^{\circ} \mathrm{C}$, July being the coldest month while October and March are the warmest. The average rainfall is between $500 \mathrm{~mm}$ and $1300 \mathrm{~mm}$. The short rains are expected in October and December while the long rains are expected in March to May. Machakos County suffers from periodic drought between February-March and August-September. The County covers an area of $6208.2 \mathrm{~km}^{2}$ and has an estimated population of 1,421,932 ( $\mathrm{GoK} 2019)$. The population density is 240 persons per $\mathrm{km}^{2}$ -and the poverty index is $59.6 \%$. Kambas are the predominant tribe of Machakos County although other tribes live and work in the county. The county practices subsistence farming of maize and drought-resistant crops such as sorghum, millet fruits, and vegetables.

\section{Makueni County}

Makueni County is located within the former Eastern Province just like her neighbor Machakos. It lies between latitude $1^{\circ} 35^{\prime}$ and $3^{\circ} 00^{\prime}$ south and longitude $37^{\circ} 10^{\prime}$ and $38^{\circ} 30^{\prime}$ east. It is populated mainly by the Kamba community although many other communities live and work there. The County occupies $8,034.7 \mathrm{~km}^{2}$ with a population of 987,653 people GoK (2019). Of the three counties under the study, it is more sparsely populated with population density of $120.9 \mathrm{per} \mathrm{km}^{2}$, though still slightly higher than the national average. The climate of the County is generally dry. The county receives low inadequate rainfall of $600 \mathrm{~mm}$ with the average temperature being $23{ }^{\circ} \mathrm{C}$ to sustain any meaningful agriculture. The residents hence experience constant crop failures and are consequently in the list of counties in need of support of relief food. To sustain their livelihood, the residents harvest sand, degrading the few seasonal water sources existing. Makueni suffers from a poor road network in contrast to the other two counties under study. 


\section{Data Collection}

Data was collected using closed ended questionnaires. There were eight Likert scale type of statements and participants were required to rank their responses, each statement on a scale of $1=$ somewhat becoming less prevalent to $5=$ becoming more prevalent. The sampler statement is "conflicts related to scarcity of firewood, such as people illegally collecting/harvesting firewood in neighbors farms, quarrelling over collection of firewood". Variable two measured participants' ranking to climate change as contributor to a list of similar statements related to conflicts to resource use according to scale $1=$ does not contribute at all to $5=$ contributes a lot. Additional sociodemographic data collected included gender of the respondent, education attainment, and age category. A total of 85 participants completed the questionnaires, comprising 30 from Makueni, 30 from Machakos, and 25 from Kiambu counties, respectively.

\section{Data Analysis}

Data was analyzed using cross-tabulation to compare percent frequency distribution by county. In addition, a one-way multivariate analysis of variance (MANOVA) between-subjects design was used to investigate the relationship between dependent variables and the independent variables, region, and gender.

\section{Results and Discussions}

\section{Sociodemographic Characteristics of the Sample}

Results of the sociodemographic characteristics of the sample are summarized in Table 1.

Table 1 Sociodemographic characteristics of the sample

\begin{tabular}{l|l|l|l|l}
\hline \multirow{2}{*}{ Variable } & Categories & $\begin{array}{l}\text { Makueni } \\
(\%)\end{array}$ & $\begin{array}{l}\text { Machakos } \\
(\%)\end{array}$ & $\begin{array}{l}\text { Kiambu } \\
(\%)\end{array}$ \\
\hline \multirow{2}{*}{ Age } & $18-29$ & $\mathbf{3 0}$ & $\mathbf{3 3 . 3}$ & $\mathbf{4 . 2}$ \\
\cline { 2 - 5 } & $30-39$ & $\mathbf{2 6 . 7}$ & $\mathbf{2 3 . 3}$ & $\mathbf{3 3 . 3}$ \\
\cline { 2 - 5 } & $40-59$ & $\mathbf{4 0 . 0}$ & $\mathbf{4 3 . 3}$ & $\mathbf{4 1 . 7}$ \\
\cline { 2 - 5 } attainment & 60 years or older & $\mathbf{3 . 3}$ & $\mathbf{0 . 0}$ & $\mathbf{2 0 . 8}$ \\
\hline \multirow{5}{*}{$\begin{array}{l}\text { Education } \\
\text { Certificate }\end{array}$} & $\mathbf{3 . 3}$ & $\mathbf{3 6 . 7}$ & $\mathbf{9 1 . 7}$ \\
\cline { 2 - 5 } & Diploma & $\mathbf{2 3 . 3}$ & $\mathbf{3 0 . 0}$ & $\mathbf{8 . 3}$ \\
\cline { 2 - 5 } & Postgraduate diploma & $\mathbf{1 6 . 7}$ & $\mathbf{6 . 7}$ & $\mathbf{0 . 0}$ \\
\cline { 2 - 5 } & Bachelor's degree & $\mathbf{4 0 . 0}$ & $\mathbf{2 3 . 3}$ & $\mathbf{0 . 0}$ \\
\cline { 2 - 5 } & $\begin{array}{l}\text { Postgraduate degree (Master } \\
\text { or PhD) }\end{array}$ & $\mathbf{1 6 . 7}$ & $\mathbf{3 . 3}$ & $\mathbf{0 . 0}$ \\
\hline
\end{tabular}


The frequency distribution in Table 1 shows that majority of respondent were in the category of age 40-59 years. Machakos had 40\%, Makueni 43.3\%, and Kiambu $41.7 \%$ in this category. Although the age bracket in this category was widespread in comparison to other categories, this category of respondents is made up of adults who have lived for a long time to experience changes brought about by climate change. Unlike those above 60 years who might suffer memory lapse, the $40-59$ years group availed information which is quite vital. The $40-59$ years category group has lived long enough to experience the changing climate patterns and conflicts over resources. It is surprising that while Kiambu had $20.8 \%$ of respondents being over 60 years, Makueni had only 3.3\%, while Machakos had none. The lowest category in age had large numbers for Makueni (30\%) and Machakos (33.3\%), while Kiambu had only $4.2 \%$.

The implication here is that climate change hardships might have lowered life expectancy in Makueni and Machakos. The higher percentage of those over 60 years in Kiambu is probably attributable to less climate change-related conflicts leading to longer life as a result of reduced stress. Alternatively, due to higher levels of development and probably having a more informed community, Kiambu County could be having people who are practicing more family planning hence a lower percentage of the young (age 18-29).

The findings in education achievement among respondents were quite amazing. It was surprising that the bulk of respondents in Kiambu had their highest education achievement being a certificate $(91.7 \%)$ and diploma (8.3\%). Makueni and Machakos which are not as highly developed had respondents with higher education and of degree and above at $56.7 \%$ and $26.3 \%$, respectively. This is probably an indicator that due to conducive climate in Kiambu, people are actively involved in production in agriculture and industry and therefore do not pursue higher education despite having very good educational facilities as compared to its counter-parts. Probably in Makueni and Machakos, unreliable rainfall forced the community to seek high level of education in order to stand a better chance of employment to earn a living. The implication here is that climate change conflicts in both Makueni and Machakos have some positive contribution.

\section{Perceptions of Impacts on Climate Change on Livelihoods}

Respondents were asked what they perceived to be the impacts of climate change on peoples' livelihoods. Results are summarized in Figs. 1, 2, and 3. Climate change has had varied negative impacts on people's livelihoods with the more serious ones being water shortage and food insecurity though Kiambu County appears not affected by water shortage. The number of women affected by the adverse effects of climate is more than that of men probably because men venture into other income earning activities. It is possible that because of the arid nature of Makueni and Machakos, women feel the pinch more as they are the ones who must trek long distances looking for water and searching for food. While it is only five males who mentioned food insecurity in Makueni, the number of females is worrying as it 


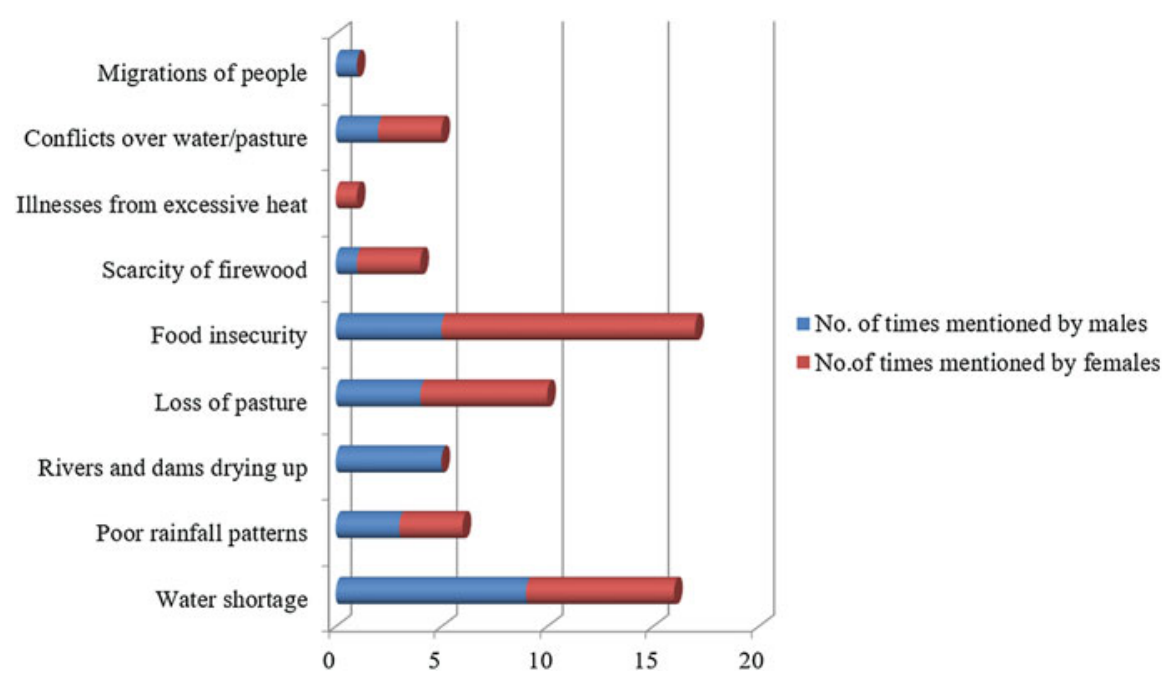

Fig. 1 Frequently mentioned impacts of climate change on livelihoods in Makueni County

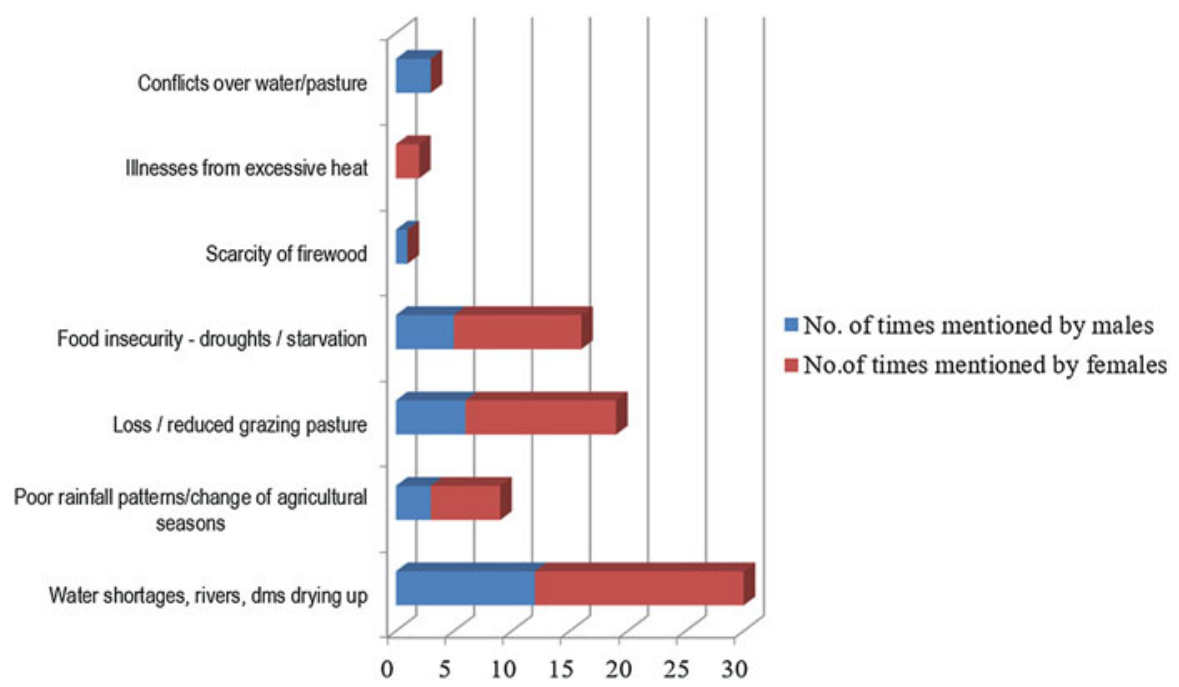

Fig. 2 Frequently mentioned impacts of climate change on livelihoods in Machakos County

stands at ten which is double that of men. In Machakos, it is surprising that while only three males mentioned that food security emanates from climate change, ten females which are more than triple the number had a similar feeling. The case of Kiambu County is different with nine males and eight females sharing a similar view. While women shoulder almost the entire burden of feeding the family in the arid counties of Makueni and Machakos with men leaving for urban centers to look for green pastures, feeding the family appears a shared burden in Kiambu. 


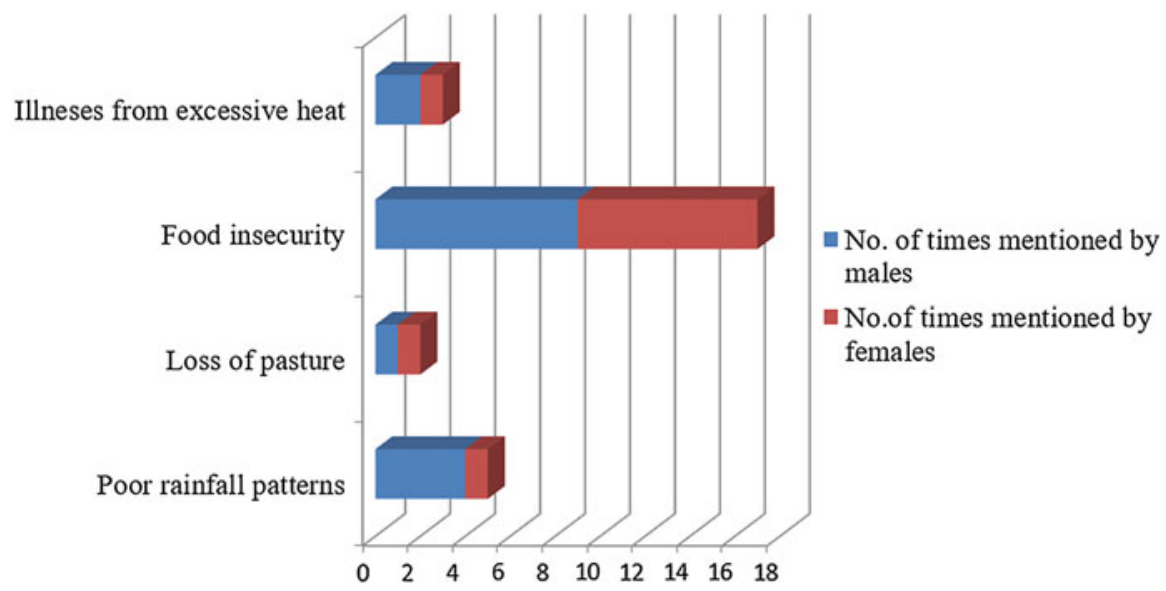

Fig. 3 Frequently mentioned impacts of climate change on livelihoods in Kiambu County

On water shortage, Makueni and Machakos feel the adverse effects of climate change. While nine males and seven females have lamented on water shortage in Makueni, a similar trend is seen in Machakos where 8 men mentioned water scarcity with the number of females almost doubling at 15. For the case of Machakos, it is surprising that more men than women lamented on water shortage. It is worth researching more on this area to establish why males would feel the pinch of water scarcity more than women. For the men reporting water shortage, it is possible that water vending is an income generating activity due to the biting water shortage in the semiarid zone. In Machakos, Kamba women and children are responsible for livestock feeding and fetching water.

Probably because of being in the highlands, Kiambu does not appear affected by water shortage. For Kiambu, having embraced the technology of water harvesting and having embraced water piping, there was no respondent who mentioned water shortage.

Wilting of plants and pasture is also felt more in Makueni and Machakos with the number of men and women being 4:6 and 6:13, respectively. In Kiambu, the numbers are a paltry $1: 1$.

Water shortage is an issue of major concern in Makueni and Machakos counties that needs quick response. Unless climate change is addressed quickly, lives will continue being threatened. It is surprising that even an area like Kiambu which is in the highlands has started experiencing food shortages occasioned by changing rain patterns due to climate change.

\section{Citizens Perceptions of the Prevalence of Climate Change Induced Resource-Based Conflicts}

Next was a Likert scale type of questions in which respondents were asked to rank prevalence of resource-based conflicts in the counties during the last 5 years. 
There were eight Likert scale type of statements and participants were required to rank their responses each on a scale of $1=$ somewhat becoming less prevalent to $5=$ becoming more prevalent. The sampler statement is "conflicts related to scarcity of firewood, such as people illegally collecting/harvesting firewood in neighbors farms, quarrelling over collection of firewood'. Respondents' responses are summarized in Table 2. Conflicts related to people illegally watering their animals in other people's water points were perceived to be becoming somewhat prevalent or more and more prevalent in Machakos at $73.4 \%$ while Kiambu had only $28 \%$ sharing this perception. Majority in Kiambu (68\% of respondents) perceived that conflicts related to a person watering their animals in someone else's water point were becoming either less or somewhat less. It is also quite striking that conflicts related to scarcity of grazing pastures are quite high in Machakos and Makueni while Kiambu reflects a very different picture. The reason for this conflict could be that the community practices both types of farming. Arable farming covers the largest part leaving a small portion for herding/grazing, unlike Kiambu residents who use zero grazing. The kind of livestock farming is an indicator of increased conflict due to scarce grazing resources. These findings are consistent with those of other researchers (Ifejika Speranza 2010). Conflicts over resources such as grazing fields and food have been reported. Over $73 \%$ of respondents in both Makueni (73.3\%) and Machakos $(80 \%)$ perceived conflicts related to scarcity of grazing pastures becoming somewhat prevalent or more and more prevalent in comparison to Kiambu which had only $36 \%$ perceiving the same. While $40 \%$ of respondents in Kiambu perceived that conflicts related to scarcity of grazing pastures were becoming less and less, none of the respondents of either Makueni or Kiambu felt the same. It was also striking that while $66.7 \%$ of respondents in Kiambu felt that conflicts related to people illegally harvesting grazing materials were becoming less and less frequent or somewhat less frequent, only $6.6 \%$ of those in Machakos felt the same. Makueni posted $29.9 \%$ with similar feeling. Conflicts related to scarcity for food had even more interesting results. While none of respondents in Machakos perceived this becoming less and less, almost half of those in Kiambu (48\%) perceived such conflicts becoming less and less prevalent. On the other hand, conflicts related to building materials were perceived to become less and less prevalent in both Makueni (30\%) and Kiambu (40\%) unlike Machakos $6.7 \%$. Conflicts related to sand harvesting also appear to be quite interesting. While well over $80 \%$ of respondents in Makueni (80\%) and Machakos (83.4\%) perceived that conflicts related to sand harvesting were on the increase, only, 22.7\% of respondents in Kiambu had a similar perception.

The probable reasons for these patterns could be the level of development of the different counties. Kiambu has posted different findings with both Makueni and Machakos probably because Kiambu is more developed. The infrastructure in Kiambu is more developed. With the good road network, transporting goods to the market is quite fast in comparison to Makueni and Machakos. Kiambu is also more cosmopolitan than both Makueni and Machakos. Although the population is predominantly Kikuyu, Kiambu is cosmopolitan and hosts other communities such as Luhya, Luo, Maasai, Kamba, Meru, and Kalenjins among others. Such people bring in new skills and enhance the growth of Kiambu. Other ethnicities include Asians and Caucasian population who are good businessmen. All these plus the fact that 


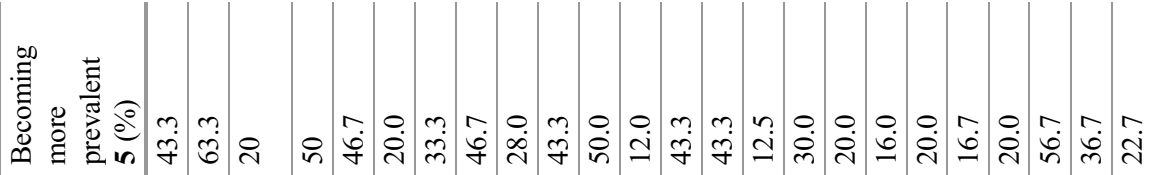

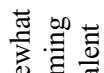

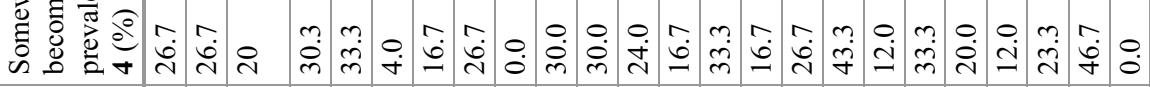

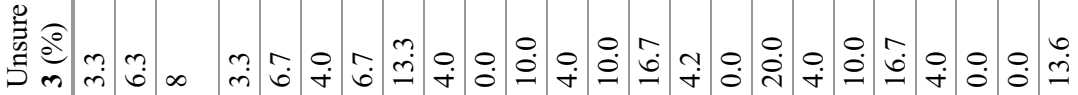

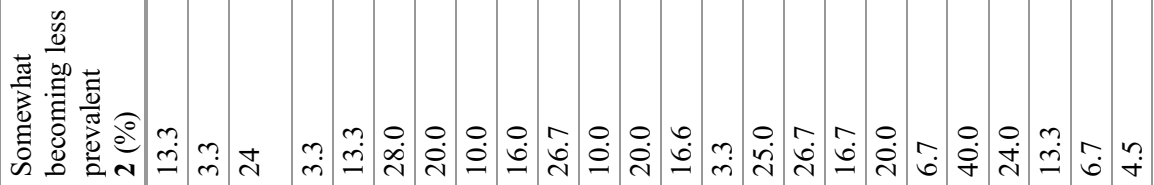

$\stackrel{8}{8}$

章营

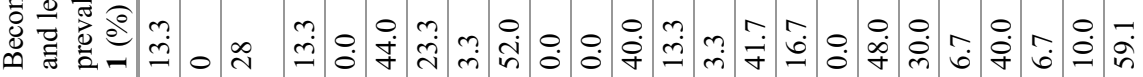

?

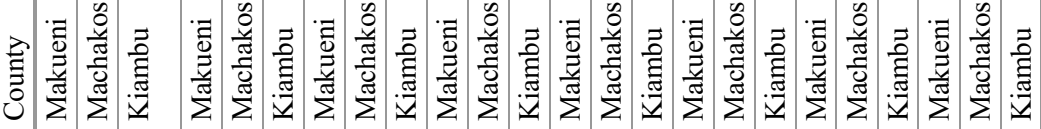

言

究

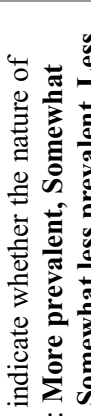

(1)

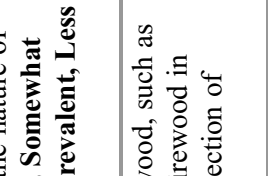

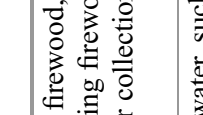

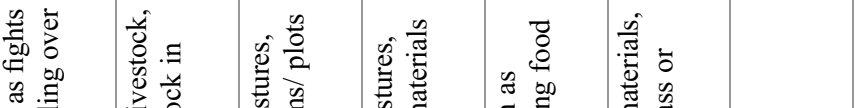

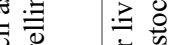

可

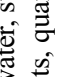

离:

눙 :

峁

殏言

运

on

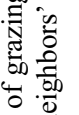

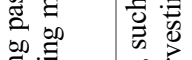

过

悹

(1)

窟

质

要

窟:

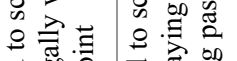

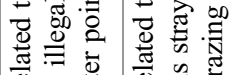

造

要

焉 总

政

焉

so 0 o

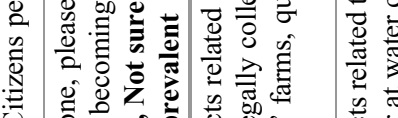

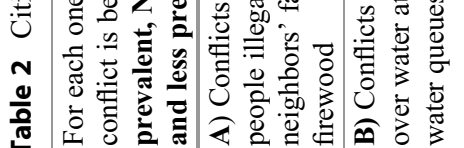

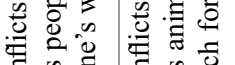

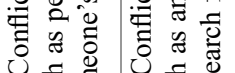

O을

记

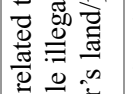

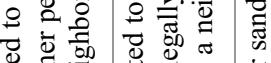

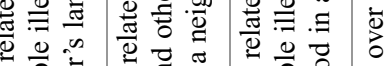

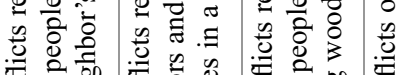

$\begin{array}{llll} & \\ & \end{array}$ 
Kiambu is a host to various foreign missions has ensured a higher income and better living standards. Another probable reason why findings for Kiambu differ significantly with those of Makueni and Machakos is climate. While Kiambu receives an aggregate rainfall of $1000 \mathrm{~mm}$ annually, both Makueni and Machakos receive less than $700 \mathrm{~mm}$ with Makueni receiving only $600 \mathrm{~mm}$ which is not adequate for a variety of crops. While Kiambu relies on major cash crops like tea and coffee and a variety of food-crops, Makueni and Machakos at times fail to harvest any food. Makueni is classified among the arid regions of Kenya.

The standard of living is higher in Kiambu as compared to Makueni and Machakos. While the poverty index is $21.75 \%$ in Kiambu, Makueni is ranked at $64.1 \%$. People in Kiambu are relatively well off with many relying on other sources of energy other than firewood. The reliable rainfall and higher living standards might also have led to individuals having their private sources of pasture and water for their animals. Again, unlike the people of Makueni and Machakos who rely on sand harvesting and charcoal burning as a source of employment, Kiambu residents are busy in the farms, industries, or working in Nairobi which is their next-door neighbor. On the other hand, the poverty index in Ukambani indicates increase household firewood conflict and more climate effects as a result of cleared indigenous trees for charcoal burning to earn a living.

The potential implications of the above are that the simmering conflicts might soon result into full-blown conflict. With well over $80 \%$ of respondents in both Makueni and Machakos perceiving that climate-related conflicts are somewhat becoming prevalent and/or becoming more and more prevalent, an alarm is starting to ring. If climate does not improve and no interventions are put in place, signs of the region emulating war-torn countries like Sudan can be predicted.

Unlike in Makueni where major policies have been passed targeting mitigating climate change, the County government of Kiambu has bills and policies concerned with improved production. Kiambu being a major agricultural and livestock production area, a bill on Abattoirs has been passed. In April 2014, the Agricultural Department Strategic Plan was launched. Some drafts on Animal Disease Bill and Veterinary services are under discussion. Revolving funds have been set aside to improve agriculture. Machakos on its part has been seeking for partnerships and investors to help develop the County and save it from climate-induced problems. Watson and Hussein Kochore (2012) while referring to the drought situation in Northern Kenya have recommended that scholars of climate change must act with speed. In a similar vein, the situation in Makueni and Machakos requires urgent attention. These research findings corroborate Watson and Hussein Kochore (2012) findings expressed in their study of Northern Kenya where the authors reported prevalence of climate change related conflicts.

\section{Citizens' Perceptions of Contribution of Climate-Change to Resource- Based Conflicts}

Next was a Likert scale type of questions in which respondents were asked to rank climate change contribution to resource-based conflicts. Results are summarized in 
Table 3. While an overwhelming $88 \%$ of Kiambu respondents perceived that climate change does not contribute a lot to conflicts related to firewood collection, a higher proportion in both Machakos and Makueni Counties shared a different opinion. Similar findings were witnessed in conflicts over water and grazing fields. While Kiambu saw almost no connection or too little between climate change and increased conflicts, with a $92 \%$, Makueni and Kiambu were in sharp contrast with $6.7 \%$ and $33 \%$, respectively. The figures for grazing pastures stood at $96 \%$ for Kiambu, $16.7 \%$ for Makueni, and only 10\% for Machakos. The same figures were posted for illegal harvesting of grazing materials except for Machakos which had nil results. The feeling of Machakos was that there was a very strong correlation between climate change and grazing pastures related conflicts. An overwhelming $90 \%$ of those in Machakos said conflicts related to scarcity of grazing pastures were either somewhat increasing or were becoming more and more prevalent. In Makueni (70\%) and Machakos $(70 \%)$, there was a major perception that climate change is contributing to illegal harvesting of food in other people's farms. Only $4.3 \%$ of respondents in Kiambu felt the same with majority in Kiambu (95.6\%) perceiving that climate change was either contributing nothing or too little to conflicts related to scarcity of food. Respondents in Kiambu saw almost no relation or a very slight relation between climate change and conflicts relating to building materials. The figure for Kiambu in this was $92 \%$, while only $40 \%$ and $36.7 \%$ of Makueni and Kiambu, respectively, perceived the same. While each of Makueni and Machakos had more than $20 \%$ of respondents saying climate change was contributing more and more in conflicts related to building materials, Kiambu posted a nil result in that line. Perhaps more surprising are the findings from conflicts over sand harvesting. While Kiambu respondents $(96 \%)$ perceived no or very slight connection between climate change and conflicts over sand harvesting, those in Makueni (73.3\%) and Machakos $(76.6 \%)$ perceived that conflicts over sand harvesting were either somewhat becoming prevalent or were becoming more and more prevalent.

Basing on what has been observed in the findings in the last 5 years; climaterelated conflicts are something to worry about. There are more conflicts over resources in both Makueni and Machakos where climate is harsh as compared to Kiambu where climate conditions are friendlier. The implication here is that the climate change being experienced across the world is likely to lead to increased conflicts.

A one-way multivariate analysis of variance (MANOVA) between subjects, design was used to investigate whether the observed differences in participants' perceptions of prevalence of resource-based conflicts, perceptions of contributions of climate change to perceived resource-based conflicts, and perceived measures by the government to mitigate conflicts differed statistically across the three regions. The two dependent variables were: (i) composite indicator of perceived resourcebased conflicts, (ii) composite indicator of perceived contribution of climate change to resource-based conflicts. The independent variable was the study region with three levels, Makueni, Machakos, and Kiambu. Results show that the differences in perceived resource-based conflicts are statistically significant $F_{2,76}=12.78$, $p<0.01$. Residents of Machakos county have a considerably higher perception that resource-based conflicts had risen during the last 5 years, $M=3.90$, followed by 


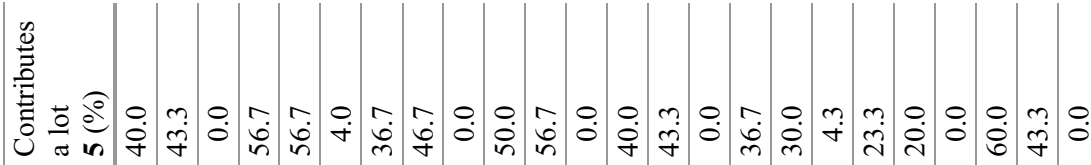
$\stackrel{0}{\leftrightarrows}$

节

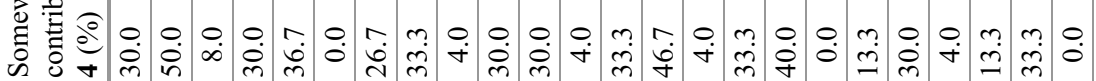

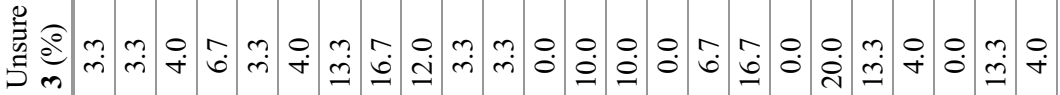
$\frac{\pi}{3}$ 竞 $\overline{\bar{c}}$

苍

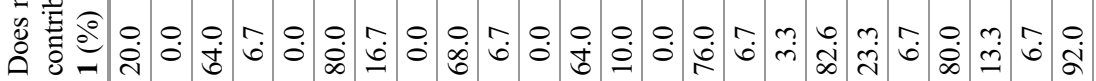

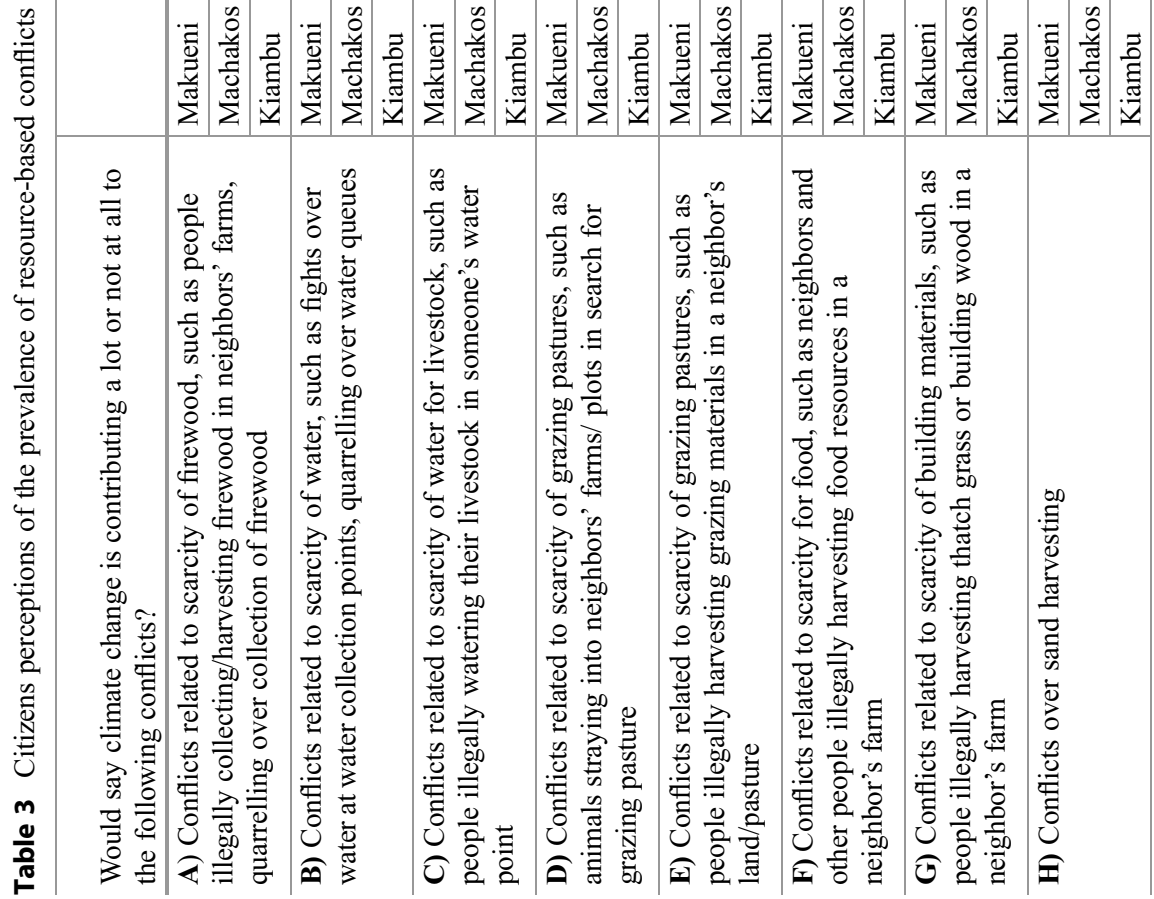


Table 4 Relationship between citizens perceptions by region

\begin{tabular}{l|l|l|l|l|l|l}
\hline Source & Dependent variable & $\begin{array}{l}\text { Sum of } \\
\text { squares }\end{array}$ & Df & $\begin{array}{l}\text { Mean } \\
\text { square }\end{array}$ & F & Sig \\
\hline Region & $\begin{array}{l}\text { Prevalence of climate change-induced } \\
\text { resource-based conflicts }\end{array}$ & 24.465 & 2 & 12.73 & 12.78 & 0.01 \\
\cline { 2 - 7 } & $\begin{array}{l}\text { Contribution of climate change to } \\
\text { resource-based conflicts }\end{array}$ & 114.41 & 2 & 57.21 & 44.07 & 0.01 \\
\hline Error & $\begin{array}{l}\text { Prevalence of climate change-induced } \\
\text { resource-based conflicts }\end{array}$ & 75.72 & 76 & 1 & & \\
\cline { 2 - 8 } & $\begin{array}{l}\text { Contribution of climate change to } \\
\text { resource-based conflicts }\end{array}$ & 98.65 & 76 & 1.30 & & \\
\hline Total & $\begin{array}{l}\text { Prevalence of climate-change-induced } \\
\text { resource-based conflicts }\end{array}$ & 1035.97 & 79 & & & \\
\cline { 2 - 8 } & $\begin{array}{l}\text { Contribution of climate change to } \\
\text { resource-based conflicts }\end{array}$ & 1094.45 & 79 & & & \\
\hline
\end{tabular}

Makueni, $\mathrm{M}=3.6$, Kiambu residents do not consider resource-based conflicts to have been on the rise during the last 5 years, $M=2.4$. Post-hoc tests using Turkey HSD revealed that the difference between perceptions from Kiambu differed statistically from those of Machakos, and also statistically from those from Makueni residents.

Results also show that the differences of perceptions in climate change as a contributor to the perceived rise in resource-based conflicts are statistically significant $F_{2,76}=44.07, p<0.01$. Residents from Machakos county have a considerably higher perception that climate change is contributing to the rise in resources-based conflicts in Machakos county, $\mathrm{M}=4.0$. Results show that Makueni follows with a relatively modest perception of climate change as a contributor to the perceived rise in resource-based conflicts, $\mathrm{M}=3.99$. Climate change is not regarded as a contributor to resource-based conflicts in Kiambu county, $\mathrm{M}=1.2$. Post-hoc tests using Turkey HSD revealed that the difference between perceptions from Kiambu differed statistically from those of Machakos, and also statistically from those from Makueni residents (Table 4).

\section{Conclusion}

This chapter explored the extent of climate change-induced resource conflicts along an hydrological gradient in three counties in Kenya, namely, Kiambu County which experiences relatively high rainfall and also high urban population, Machakos County, which generally experiences modest rainfall availability, and Makueni County regarded to be one of the most arid and semiarid counties in Kenya. Variability in the severity of climate change-induced resource-based conflicts was evident in counties along rainfall availability gradient. The impacts of climate change can be diverse, particularly for vulnerable regions such as arid and semiarid regions such as Makueni County. Respondents from Makueni County mentioned the 
highest number of climate-related impacts in the county, with the most frequently mentioned impact being increasing food insecurity followed by increasing water shortages. Machakos followed with respondents mentioning seven impacts that included increased water shortages and scarcity of pasture. In Kiambu County, only four impacts were mentioned with food insecurity being frequently mentioned among the list of impacts of climate change in the county. Results of the descriptive and inferential statistics reveal that resource-based conflicts vary along the hydrological gradient. Residents in Machakos County perceived resource-based conflicts to have risen quite significantly during the last 5 years, compared to perceptions from Makueni County. Kiambu residents did not consider resource-based conflicts to have risen during the last 5 years. Also, residents of Machakos County perceived climate change to be a factor in the rise of resource-based conflicts compared to perceptions from their counter parts from Makueni County. Although Makueni is the driest of the three counties, the publicity of the government's investments towards climate change mitigation and adaptation offers a possible explanation on the differences in survey results compared to residents' perceptions from Machakos County.

\section{Suggestions for Further Research}

Follow up research is needed to examine if survey results correlate with field observations in terms of reported climate change resource-based conflicts, different government and nongovernment agencies' investments and expenditures on climate change mitigation and adaptation, especially citizens participation in those projects. In addition, further studies are needed to investigate the self-reported food insecurity associated with climate change, the coping capacity under different resource, socioeconomic and sociocultural settings, the consequences on malnutrition particularly on vulnerable population, and impacts on population health.

\section{References}

Agnew R (2012) Reflection on “A revised strain theory of delinquency”. Soc Forces 91(1):33-38. Researchgate

Benjaminsen TA, Ba B (2009) Farmer-herder conflicts, pastoral marginalisation and corruption: a case study from the inland Niger Delta of Mali. Geogr J 175(1):71-81. https://doi.org/10.1111/ j.1475-4959.2008.00312.x. Wiley Press Room, Published online

Benjaminsen TA, Maganga FP, Abdallah JM (2009) The Kilosa killings: political ecology of a farmer-herder conflict in Tanzania. Dev Chang 40(3):423-445. https://doi.org/10.1111/ j.1467-7660.2009.01558.x. Wiley Online Library

Folami OM, Folami AO (2013) Climate change and inter-ethnic conflict in Nigeria. Peace Rev 25(1):104-110. https://doi.org/10.1080/10402659.2013.759783. Published online

GoK. (2019). 2019 Kenya Population and Housing Census Volume I: Population by County and Sub-County. Government Printer. https://www.knbs.or.ke/?wpdmpro=2019-kenya-populationand-housing-census-volume-i-population-by-county-and-sub-county 
Hadush M (2018) Welfare and food security response of animal feed and water resource scarcity in Northern Ethiopia. Agric Food Econ 6(1):22. https://doi.org/10.1186/s40100-018-0116-2. Norwich

Hussein K, Sumberg J, Seddon D (1999) Increasing violent conflict between herders and farmers in Africa: claims and evidence. Dev Policy Rev 17(4):397. Blackwell Publishers Ltd

Ifejika Speranza C (2010) Drought coping and adaptation strategies: understanding adaptations to climate change in agro-pastoral livestock production in Makueni District, Kenya. Eur J Dev Res 22(5):623-642. https://doi.org/10.1057/ejdr.2010.39. Bonn

Kuhlmann M, Guo D, Veldtman R, Donaldson J (2012) Consequences of warming up a hotspot: species range shifts within a centre of bee diversity. Divers Distrib 18(9):885-897. https://doi. org/10.1111/j.1472-4642.2011.00877.x. Blackwell Publishing Ltd

Meierding E (2013) Climate change and conflict: avoiding small talk about the weather. Int Stud Rev 15(2):185-203. https://doi.org/10.1111/misr.12030

Peters K, Mayhew L (2019) Climate change, conflict and security scan. Overseas Development Institute, London, p 57

Price R (2019) Climate change as a driver of conflict in Afghanistan and other fragile and conflict affected states. Institute of Development Studies, vol 18. Assets Publishing Service, Brighton, UK

Scott SV, Andrade RCD (2012) The global response to climate change: can the security council assume a lead role? Brown J World Aff 18(2):215-226. University of New South

Serdeczny O, Adams S, Baarsch F, Coumou D, Robinson A, Hare W, ... Reinhardt J (2017) Climate change impacts in sub-Saharan Africa: from physical changes to their social repercussions. Reg Environ Chang 17(6):1585-1600. https://doi.org/10.1007/s10113-0150910-2. Berlin

Sunga LS (2014) Does climate change worsen resource scarcity and cause violent ethnic conflict? Int J Minor Group Rights 21(1):1-24. https://doi.org/10.1163/15718115-02101001.CNA

Watson EE, Hussein Kochore H (2012) Religion and climate change in Northern Kenya: new moral frameworks for new environmental challenges? J Study Relig Nat Cult 6(3):319-343. https:// doi.org/10.1558/jsrnc.v6i3.319. Equinox Publishing, Sheffield

Witsenburg KM, Adano WR (2009) Of rain and raids: violent livestock raiding in Northern Kenya. Civil Wars 11(4):514-538. https://doi.org/10.1080/13698240903403915. Halle/Saale

Open Access This chapter is licensed under the terms of the Creative Commons Attribution 4.0 International License (http://creativecommons.org/licenses/by/4.0/), which permits use, sharing, adaptation, distribution and reproduction in any medium or format, as long as you give appropriate credit to the original author(s) and the source, provide a link to the Creative Commons license and indicate if changes were made.

The images or other third party material in this chapter are included in the chapter's Creative Commons license, unless indicated otherwise in a credit line to the material. If material is not included in the chapter's Creative Commons license and your intended use is not permitted by statutory regulation or exceeds the permitted use, you will need to obtain permission directly from the copyright holder.

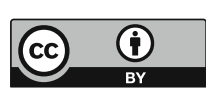

